\title{
Advancing Health Promotion Pedagogy: A Multi-Step, Applied Health Promotion Classroom Project
}

\author{
Jennifer D. Irwin \\ School of Health Studies, Faculty of Health Sciences at Western University in London, London, ON, Canada \\ Email: jenirwin@uwo.ca
}

Received 29 March 2016; accepted 7 May 2016; published 10 May 2016

Copyright (C) 2016 by author and Scientific Research Publishing Inc.

This work is licensed under the Creative Commons Attribution International License (CC BY).

http://creativecommons.org/licenses/by/4.0/

(c) (i) Open Access

\begin{abstract}
Courses that bridge health promotion scholarship with a demonstrative application of that scholarship are potent and critical for future public health professionals. For senior students about to graduate from the Honors Bachelor of Health Sciences (BHSc) Program at Western University (Ontario, Canada), my intention was to create a course experience that marries health promotion scholarship with a practical skill-set in line with constructivist learning approaches. This article outlines a multi-component, classroom-based, population health group project for senior students enrolled in an Advanced Health Promotion course. Since its inception, the course has hosted 562 students and has received an average evaluation of 6.4/7.0 on the overall course experience. The specific requirements of the needs assessment, epidemiological assessment, social marketing campaign, implementation evaluation, and project summary, as well as strategies to facilitate positive group dynamics are presented.
\end{abstract}

\section{Keywords}

Course Development, Undergraduate, Health Promotion, Public Health, Constructivism

\section{Introduction}

Innovative health promotion course experiences are important for training the next generation of public health professionals. It seems a reasonable expectation that students with a background in health promotion be well versed both in its scholarship and in the "doing"/practical application of health promotion activities upon securing a position in the field. Western University (Ontario, Canada) prides itself on delivering “... an exemplary learning experience that engages the best and brightest people challenging them to meet ever-higher standards in 
the classroom and beyond” (Western University, 2016). For senior students about to graduate from the Honors Bachelor of Health Sciences (BHSc) Program, my intention was to create a course experience that marries health promotion scholarship with a practical skill-set, informed by the constructivism philosophy of learning (Karagiorgi \& Symeou, 2005). That is, the course is designed to encourage students to make meaning from and apply the health promotion scholarship learned in their introductory course to real-world health challenges present among the study body, to integrate their experiential learning with academic literature, and to reflect on their overall learning throughout the course. The course staff (myself as the Instructor and the Graduate Teaching Assistant) serve to guide students through the multiple stages of the project and prompt further inquiry, rather than provide right/wrong answers to questions. This manuscript is not intended to serve as an education in what is health promotion (please refer to McKenzie et al., 2013 for such content), but instead, the purpose of this paper is to share details of the course and the experiential course project in the collaborative spirit of health promotion initiatives in curricula design. My hope is that readers who teach courses in health education and/or health promotion may find the content useful for their own offerings.

Because the details of the course project are iterative and numerous, this manuscript is organized into six parts; it begins with the larger context of how and why the course was developed, followed by an explanation of what is contained on the course syllabus; then the more detailed information about the project contained within the course's "project guide" created to help support students through their learning process. The rationale for using, and clauses contained within the "group contract" is then presented. Finally, the details of each component of the project itself are presented along with information about how the course has been evaluated by students since its inception.

\subsection{Part 1: Course Development}

Thirteen years ago an Advanced Health Promotion (AHP) course (the primary focus of this article) was developed as an application of material from the introductory offering that second and third year BHSc students take as a mandatory part of their curriculum. The introductory course focuses on the planning, implementation, and evaluation of health promotion programs (course textbook by McKenzie, Neiger, \& Thackeray, 2013). Whereas the introductory health promotion course hosts an average of 350 students each year, the advanced senior-level course was designed for a smaller number of students (18 - 100/year depending on other course options). The AHP course was created to serve as a "bridge" between scholarship in health promotion and the application of that scholarship through students' active engagement in a "real world”, group-conducted population-based project. The course is offered over one term (12 weeks) for three consecutive hours/week and is considered a designated essay course-a written assignment of at least 1500 words is a requirement. The AHP course is mandatory for students enrolled in the 4-year, Honors Specialization in Health Sciences-Health Promotion. That said, a portion of students take is as an elective course.

\subsection{Part 2: Course Syllabus}

The 6-page course syllabus presents the general overview of the entire course. It begins with the course staff information, including the office locations and office hours of the Instructor and Teaching Assistant(s) (TAs). Students are then reminded of the course pre-requisites and are advised that the textbook from the Introductory Health Promotion course, online readings, and the newest edition of the Publication Manual of the American Psychological Association (APA, 2010) are needed materials. The course description explains that this AHP course expands upon the program planning, implementation, and evaluation content of the Introductory Health Promotion course that they took previously. The description goes on to state that in particular, this course focuses on the application of health promotion programming principles. Upon completion of this course, the learning objectives listed for the students state that they should be able to: use micro- and macro-based health promotion strategies; compose clear program objectives and goals; conduct a needs assessment; conduct an epidemiological assessment; prepare and present a social marketing campaign; conduct an implementation evaluation; and work in the mind- and behavior-set of a professional in a group situation. The categories and weights for the course evaluation are presented, with the group-based course project counting $70 \%$ toward their final grade; their participation in another group project worth $2 \%$; the grade received from their group members' evaluation of each person's contribution counting as 5\%; and the final exam makes up the remaining $23 \%$ of the course grade. The fact that $90 \%$ attendance is required to pass the course is highlighted to ensure its importance is un- 
derscored. The course structure is explained - the first third of each class is spent providing students with lecture content and current research in health promotion related to the various elements of the major project; the last two thirds of each class is spent with students in groups actively applying that scholarship to their project and interacting with course staff. The next two syllabus pages introduce the multi-stage, population-based project that begins during the first class. The university's required information about the policies regarding use of electronic devices in the classroom, the Student Code of Conduct, accommodation for Illness or other absences, scholastic offenses, and support services are listed with relevant links. Finally, the week-by-week course schedule is provided.

\subsection{Part 3: Project Guide}

More detailed than the course syllabus, an instructor-derived 10-page guide/booklet, entitled "How to write great needs assessments, epidemiological assessments, social marketing campaigns, evaluations, and executive summaries" is posted on the course website for students to download. Students are told that it is in their best interest to have the guide available for all classes and group meetings. A preamble explains that the details included in the guide are to be used in combination with the information provided on the course syllabus as well as the content provided during the lecture portion of each class. Furthermore, because the course is intended to serve as a bridge toward working as a health professional (whether in an employed job or via graduate/professsional school), the standards required at that level are employed. Specifically, careless errors will not be ignored, late assignments are penalized severely, and polished, professional documents are expected. Students are advised that each aspect of the project will be graded with the assumption that every person in the group has reviewed every project-related detail provided and has read and approved of the document submitted by the group. Following the preamble, a list of check-boxes are provided to help students confirm that they have addressed each required aspect (e.g., specific content components, APA referencing and writing style, number of pages, formatting requirements) for each of the five components of the course project (i.e., needs assessment, epidemiological assessment, social marketing campaign, implementation evaluation, and executive summary). Then, an evaluation scheme/marking key is provided so that students are completely appraised of instructor expectations.

\subsection{Part 4: Group Contract}

To be as real-to-professional-life as possible, groups of four to five students are established at random by course staff prior to the first day of class, and membership is revealed during the first class because that is when the group project begins. Within the first week, groups are required to identify which member will "captain" which section of the 5-step project and within two weeks each group is required to complete and have each member sign an "expectations contract" that is submitted to course staff. A sample contract (Appendix) is provided online and groups are encouraged to identify whichever clauses they determine will be important for their smoothest progression through the project. Rarely do students alter the sample contract. The contract was introduced about 6 years into the course and, from an Instructor perspective, has helped to enhance positive group dynamics by reducing group tensions because everyone knows their agreements and, by signing the contract, they explicitly take responsibility for their role.

\subsection{Part 5: Project Components}

Nine weeks of the course (i.e., $75 \%$ of course time) are dedicated to the project. Groups choose a health-related topic relevant to senior level university students (e.g., eating healthy on campus, physical activity, safer sex), the population of focus given the membership of the class represents the target audience (i.e., undergraduate students).

Needs assessment. Each group is responsible for identifying $6-8$ questions for their need assessment's semi-structured interview guide. The groups create the questions themselves and staff feedback and guidance are given to each group to ensure the questions use open-ended wording; tap into gaining an understanding of what participants feel is important about the topic; target the barriers and facilitators to healthier choices regarding the topic; elicit the components of an effective program to address the topic; and probe how their program should be advertised to get best uptake by the target audience. Groups are then required to conduct their needs assessment (worth 15\% of each group's grade) on that topic using focus group methods with members of the class as par- 
ticipants (although not ideal to mimic a true needs assessment study, each group conducts only 1 focus group due to time constraints of the one-term course). Students are also encouraged to design a survey that will contribute meaningfully to the needs assessment data. Initially my intention for the course was for groups to enroll members of the university community either to complete surveys or conduct focus groups, but the ethical requirements of completing the forms and waiting for approval meant that the course would be over prior to the project being able to commence; thus the project is conducted entirely within the course context and membership.

Students are mandated to use focus groups as the needs assessment approach because it allows all members of the group and class to participate actively as researchers and participants, and because focus groups are a suitable method for identifying the specific needs and wants of the target audience (McKenzie et al., 2013). In the 7 10 page needs assessment write-up (not including appendices), groups must include the broad topic they chose to research (e.g., drinking alcohol in moderation); an explanation of the methodological approach used to conduct the needs assessment (i.e., focus groups) and analysis (i.e., inductive content analysis); the main findings from the focus group (with quotations); and a summary of the findings. Furthermore, the strategies used to help support the trustworthiness of the focus group data (as described by Guba \& Lincoln, 1989) are to be included (e.g., providing thick rich description of the focus group setting and context to help support the dependability of the data; having multiple-coders to help support the confirmability of the data). A copy of the semi-structured interview guide and transcriptions as well as "field notes" from the focus group are to form the write-up's appendices. Groups are responsible for identifying the names and student numbers of the people who participated in their needs assessment, and providing this information to the course staff at the start of the class following their focus group session; this record is used to assign the $2 \%$ for participation.

Epidemiological assessment. The epidemiological assessment (worth $15 \%$ of each group's grade) is the next step. Students are responsible for identifying a minimum of 5 pieces of pertinent (and current) primary source academic journal articles regarding the population of undergraduates and health topic chosen. They are to provide a brief literature review of the major prevalence data regarding their topic area (e.g., prevalence of students who are inactive, numbers impacted by inactivity-related disorders, human and financial costs associated with this population's inactivity). They are asked to identify literature on evaluated health promotion programs that address their topic, summarize the key program components and findings inclusive of the health behavior theory/theories used to inform the program, and explain how this knowledge can be used to inform future programming. Students are told that it is helpful if they can provide some epidemiologic data on the major theme(s) from their needs assessment. For example, students in the focus group identified the importance of "time" when promoting physical activity programs - What has previous research identified about how often "time" is cited as important for physical activity programs? At this point, groups have conducted their needs assessment, and have gone through the relevant epidemiologic data, all of which enables them to identify the more specific direction of the rest of their health promotion project. At the end of the epidemiological assessment write-up, students are to reflect on what they have learned from integrating the needs assessment and epidemiological assessment findings, and from this integration, they are to identify what will be the more specific focus of their social marketing campaign (e.g., the research they have conducted to date leads them to identify that they will focus on creating and advertising a program to enhance physical activity that is inexpensive, social/group-based, and takes minimal time).

Social marketing campaign. The social marketing campaign (write-up worth $10 \%$ and presentation worth 10\%) tends to be students' favorite part of the project. This aspect of the project taps into their creativity, passion, commitment, and seems to be the component that makes the project feel very real for students. In fact, it is often necessary to halt their enthusiasm in creating the campaign prior to actually conducting the needs and epidemiological assessments (given the campaign is to be based on the integration of what the target audience's needs assessment and previous research reveals). To illustrate the creativity that is typical of the students, one year, as part of their "safer sex" program, a group created and presented to the class, a humorous commercial to advertise a condom wrapper with the picture of a purple bucking mustang on it, and the tag line, "Ride Western Style" (the mascot of Western University is a mustang and the school colors are purple and white). The idea was to make these particular condoms a 'fun and cool' thing to be seen with, rather than provoke embarrassment or shame (which had been identified through their needs and epidemiological assessments as a barrier to students' safer sex practices).

The social marketing write-up must include an overview of their health promotion program, how they incor- 
porated the "4 P's" (Price, Product, Place, and Promotion) of social marketing as well as the components they considered within the context of "Exchange Theory" (McKenzie, Neiger, \& Thackeray, 2013). The campaign itself is to be a short (3 - 5 minute) advertisement/commercial for their program that is experienced as engaging by the target audience (i.e., evoke a feeling among the audience such as fun or motivation with messaging that genuinely captures their interest and desire to know more about the program and products being advertised). Students who serve as the focus group participants for each group are involved in the social marketing campaign grading, given they were the ones who identified what needs they wanted met (i.e., $50 \%$ of the campaign grade of $10 \%$ is provided by the focus group participants).

Project evaluation. Due to the one-term reality of the course, a 5-page implementation evaluation (worth 10\%) of each group's process is the type of evaluation conducted for the project. No other types of evaluations typical of health promotion programs are suitable as they require more time for the program to be implemented. In this document, groups are to reflect on their experience with all aspects of the project-what went well, what did not go well, what they learned as a result of the process, and what advice they would give future groups engaging in this project.

Executive summary. Finally, a parsimonious (2 - 4 page) executive summary (worth 10\%) of the entire project is required. In essence, this is a long abstract of the project components, from start to finish. This is often the section with which students struggle the most, as it requires brevity and group consensus about which information to include and exclude in service of providing a comprehensive overview of the entire project.

Group members' evaluations of each other. During the final exam, when nobody can see what others are writing, students are asked to complete an evaluation of their group members on a Likert scale anchored between one and five (strongly disagree and strongly agree, respectively, with most of the criteria provided below:

- This individual attended all meetings for their full duration (unless previously arranged in which case he/she made up for the time lost);

- He/she contributed fully at the meetings and to the work (written and otherwise);

- This individual took initiative in getting the group organized regarding the section for which he/she was team captain (and clearly understood the section for which he/she was leading as well as the other sections of the project);

- This individual worked well with the others, made clear attempts to foster team cohesiveness, and was a reliable and dependable member of the group.

Students are told that it would be unusual for everyone in the group to receive top marks on this, and that if course staff perceives that deals have been made to give everyone in the group $5 / 5$, the evaluations will not be used. When $5 / 5$ is given for all group members, students are required to provide further justification explaining their ratings. Students seem to respect the process as evidenced by the varied ratings within each group each year.

\subsection{Part 6: Course Evaluations}

Each course at the university is evaluated on a yearly basis, through anonymous participation by students in the classes. Since its inception, the AHP course has hosted 562 students and has received an average evaluation of 6.4/7.0 on the overall course experience. The qualitative commentary that accompanies the quantitative evaluations is consistent in its inconsistency each year. More specifically, each year, students comment on how they both loved and despised not having control over whom their group members were, and the anxiety and value associated with the group project. Consistently each year, students express gratitude for the practical skills learned throughout the duration of the term and especially the group project. Anecdotally, as the instructor of the course, I tend to get many emails from students a year to two after they graduate, expressing their appreciation for the group project because it helped to prepare them for working in public health and with colleagues they find challenging.

\section{Discussion and Lessons Learned}

As the Instructor, the course has been one of the most fulfilling course experiences in my 19 years on faculty. It requires quick and extensive feedback to students and a high level of commitment to the course in general. There's much less lecture preparation time and more time engaging with students, prompting critical inquiry, 
and helping to develop students' writing. It's an inspirational experience to learn with these students each year.

The AHP course and the details of the course project have evolved over the 13 years it has been offered, and during this time I, as the Instructor, have learned as much from students as they have learned from the course. During this time, students have become more techno-savvy than I could imagine for my own skills, and the age gap between us has widened. Consequently, this has resulted in me having less tangible knowledge about what it is like to be a student in today's world. From reviewing the projects, I've learned that the social nuances have shifted from when I was a student, and the financial and educational performance burdens have seemingly increased. As a result, I believe I have a greater, more empathetic understanding of and for this population of (primarily) young adults. The topics they choose as relevant for their cohort have shifted, and while foci on moderate alcohol consumption and safer-sex practices, for instance, remain a staple each year, anxieties about the future and financial strain have been chosen more often the last few years, while healthy eating on campus has received less focus as healthier campus options have increased. I have also noticed a shift in writing quality over the years, with most recent cohorts struggling more with essay writing than earliest cohorts, perhaps a result of mostly large classes and predominantly multiple-choice exam evaluations. In essence, the course has and continues to serve as a constructivist learning experience for me about what it is like to be a senior health sciences' undergraduate student, their view of the primary health issues most concerning for their cohort, and their learning challenges; that is, through all aspects of the course project I am gifted with the opportunity to learn more about students as whole entities, including how they perceive their roles and what meanings they attribute to the health topics they identify as most concerning for their cohort.

In addition to the value it offers course instructors, as noted above, it is my belief and experience that constructivism (Karagiorgi \& Symeou, 2005) has served, and continues to serve, as an ideal approach to guide the design of the AHP course project, for a number of reasons. Working from the assumption that senior health sciences students are motivated to earn high grades, they are informed that the only way to succeed in the course is to actually learn - to do so they must actively participate in all aspects of the project and to attempt to find meaning from each component; there are no "right or wrong" answers throughout the project, but instead, students are provided with a written guide and course staff who are committed to support the learning they are finding and sharing. As a group, students have the autonomy to choose health topics about which they engage in a series of learning challenges (i.e., project components) that they use to create, integrate, and debate layers of meaning in service of facilitating others' healthier choices Each group analyzes, comes to consensus about, and integrates learnings from the needs and epidemiological assessments to determine exactly what their health promotion program will focus on, and then they must apply those learnings to relevant social marketing concepts in order to design and present a health promotion program advertisement that is relevant and attention-grabbing for the target audience. Although a fairly laborious role for the course staff, it is essential that each project component's write-up is returned to students with an abundance of feedback and critical questions that they are encouraged to consider as they engage with the next components of the project, making the assessments critical components of their learning processes, a keystone of the constructivism approach. The use of constructivism to inform the course project has meant that each group, each year, has its own unique experience; even though many topics repeat each year, there have never been two projects that are exactly alike (and, in fact, most are very distinctive and unlike any other project).

For others interested in including in their course offerings, the type of project described in this manuscript, I suggest paying close attention each year to the insights and advice students offer future students within the Implementation Evaluation section of the project write-up. Many of the project "tweaks" have been taken from these insights, including the use of the required group contract to enhance group dynamics and ameliorate project completion. Lastly, overall the project is often a "messy" experience for the group members, fraught with frustrations regarding the sharing of leadership roles, negotiations among different writing/learning/presentation styles and personalities, and debates about the meanings they are constructing around their project findings. I tell each class that if, at some point during the process, they feel completely out of control and incredibly frustrated, that's probably a good sign that everything is exactly on track.

\section{References}

APA (2010). Publication Manual of the American Psychological Association (6th ed.). Washington, DC: American Psychological Association. 
Guba, E. G., \& Lincoln, Y. S. (1989). Fourth Generation Evaluation. Newbury Park, CA: Sage Publications.

Karagiorgi, Y., \& Symeou, L. (2005).Translating Constructivism into Instructional Design: Potential and Limitations. Educational Technology \& Society, 8, 17-27.

McKenzie, J. F., Neiger, B. L., \& Thackeray, R. (2013). Planning, Implementing and Evaluating Health Promotion Programs (6th ed.). Toronto: Pearson.

Western University (2016). Who We Are. http://www.uwo.ca/about/whoweare/index.html.

\section{Appendix: Sample Group Contract for Advanced Health Promotion Project}

As a member of this group, I agree to fulfill the following expectations of my group:

- I will respect other people (I will listen openly to their ideas, suggestions and concerns);

- I will contribute ideas and suggestions to my group's work;

- I will make sure that group-imposed deadlines will be overtly stated (e.g., if a project is due to be handed in on Friday, everybody will have their contribution to the project captain by Tuesday);

- I will turn in my contributions, in full, for each project on time;

- I intend to attend all group meetings in their entirety, and when it is absolutely unavoidable, I will contact my group members to let them know that I will be late/absent well in advance of the meeting (i.e., 24 hours). I will take responsibility to catch-up on what I missed AS SOON AS POSSIBLE after the meeting;

- With regard to the project for which I am team captain, I will take responsibility to set-up and lead my group's meetings, communications, task-assignment; I will make sure that I fully understand the requirements and needs of the project; and I will make sure that the project will be completed on time;

- If I perceive that there are any problems within our group that are negatively impacting our work, I will respectfully bring up my concern(s) to the group in order to make our working relationship more productive. I will respectfully and non-defensively listen to concerns brought up by other group members, and I realize that their intent is to facilitate the fixing of any problems, rather than causing new ones; **this clause is not optional**;

- Although our group will attempt to deal with our problems on our own, I will inform the course Instructor of on-going concerns as they arise, as well as how they are being addressed. **this clause is not optional**. Signatures of Group Members: 